\title{
Exigência de proteína bruta para codornas europeias
}

\author{
Crude protein requirements for European quails
Carlos Eduardo Belinghausen Merseguel ${ }^{1}$, Maria Fernanda de Castro Burbarelli ${ }^{1 *}$, Gustavo do Valle Polycarpo $^{2}$, Roberto de Andrade Bordin ${ }^{3}$, Maria Estela Gaglianone Moro ${ }^{4}$ e Ricardo Albuquerque ${ }^{1}$

\author{
1Universidade de São Paulo, São Paulo, SP, Brasil.* Autor para correspondência: mfcb@usp.br. \\ 'Universidade Estadual Paulista "Júlio de Mesquita Filho", Dracena, SP, Brasil. \\ ${ }^{3}$ Faculdade de Tecnologia Estadual, Mogi das Cruzes, SP, Brasil. \\ ${ }^{4}$ Universidade de São Paulo, Pirassununga, SP, Brasil.
}

Submissão: 26/02/2018 / Aceite: 01/03/2019

\begin{abstract}
RESUMO
A precisão no atendimento das exigências nutricionais é de grande importância na produção de codornas, porém há ausência de consenso quanto às recomendações de proteína bruta (PB) para codornas de linhagens específicas para corte. O presente estudo teve como objetivo determinar a exigência de PB para codornas europeias sobre o desempenho e sobre as características de carcaça. Foi utilizado o delineamento inteiramente casualizado em esquema fatorial $5 \times 2$, sendo cinco níveis de PB para machos e fêmeas. Na fase inicial (1 a 21dias), foram utilizadas 1.800 codornas e níveis de PB de 20,0, 22,5, 25,0, 27,5 e $30,0 \%$, com seis repetições contendo 30 aves cada. Na fase de crescimento (22 a 45 dias), foram usadas 1.620 codornas e níveis de PB de 17,5, 19,5, 22,0, 24,5 e 27,0\%, com seis repetições contendo 27 aves cada. As dietas foram fareladas a base de milho e farelo de soja. O desempenho das codornas foi avaliado ao final de cada período, e o rendimento de carcaça no 45 dia. Aos 21 dias houve maior ganho de peso e melhor conversão alimentar, independentemente do sexo, com 25,50\% e 27,06\% de PB, respectivamente. No período de 22 a 45 dias, observou-se somente efeito do sexo, sendo que as fêmeas obtiveram desempenho superior. Com relação às características de carcaça, os machos obtiveram maior rendimento de carcaças (quente, fria e dorso); já as fêmeas, apresentaram maior rendimento de cortes (peito, moela e fígado).
\end{abstract}

PALAVRAS-CHAVE: codorna de corte, desempenho, exigência nutricional, proteína bruta, qualidade de carcaça.

\begin{abstract}
Accuracy in meeting nutritional requirements has great importance in quail nutrition however there is a lack of consensus on crude protein (CP) recommendations specific for European quails. The present study aimed to define crude protein requirements for European quails on performance and carcass characteristics. A completely randomized design was used in a $5 \times 2$ factorial scheme, with five CP levels for male and female quails. In the starting phase (1 to 21 days) it was used 1,800 quails and CP levels were $20,0,22,5,25,0,27,5$ and $30,0 \%$, with six replicates containing 30 birds each. In the growth phase (22 to 45 days) it was used 1.620 quails and CP levels were 17,5, 19,5, 22,0, 24,5 and 27,0\%, with six replicates containing 27 birds each. Theirs $d$ was a corn soybean based diet in grounded form. The performance of the quails was evaluated in the end of each experimental phase and carcass yield in 45 days. Weight gain and feed conversion ratio was higher for $25,50 \%$ and $27,06 \%$ respectively, regardless of gender, in 21 days. In the growth phase, it was observed just gender effect in which female quails had higher performance. For carcass characteristics, male quails obtained higher carcass and dorse yield and female quails higher breast, liver and gizzard yields.
\end{abstract}

KEYWORDS: European quails, performance, nutritional requirements, crude protein, quality carcasses.

\section{INTRODUÇÃO}

Durante décadas a carne de codornas no Brasil era proveniente de aves de postura em final de produção destinadas ao abate. Com a introdução das linhagens específicas para corte, como a codorna europeia (Coturnix coturnix), iniciou-se a produção de carcaças maiores e com carnes mais macias, sem a perda de seu diferenciado sabor (REZENDE et al. 2004). No entanto, devido aos maiores índices de ganho 
de peso, a codorna europeia apresenta diferenças nas exigências nutricionais com relação à codorna de postura. É sabido que a falta de proteína bruta (PB) na dieta pode diminuir o desempenho das codornas, assim como o excesso o prejudica. Altas doses de PB eleva o custo da formulação da dieta, incrementa 0 gasto metabólico e aumenta a excreção de nitrogênio (ALETOR et al. 2000, BREGENDAHL et al. 2002).

Escassas informações ou divergências são encontradas na literatura a respeito de codornas europeias, a exemplo temos as Tabelas Brasileiras para Aves e Suínos (ROSTAGNO et al. 2005) nas quais são encontradas referências nacionais de valores de exigências nutricionais; no entanto, apresentam apenas informações sobre linhagens de postura (Coturnix japonica). Outra fonte para consultas é o NRC (1994), que além de não retratar as exigências sob condições brasileiras, também só aborda linhagens de postura.

Já nas Tabelas para Codornas Japonesas e Europeias de SILVA \& COSTA (2009), referência nacional, podem ser encontradas recomendações de PB em dietas para codornas de corte de $25 \%$ e $22 \%$ para a fase inicial e final, respectivamente. Porém quando comparadas à literatura demonstram divergências. CORRÊA et al. (2008) encontraram máximo ganho de peso de codornas europeias com proteína acima de $28 \%$ para o período de 7 a 14 dias, $26 \%$ para o período de 15 a 28 dias e de $24 \%$ para o período de 29 a 35 dias. REZENDE et al. (2004) encontraram melhor resultado com apenas $20,5 \%$ de proteína para a fase inicial. VELOSO et al. (2012) recomendaram a dose de $26 \%$ de proteína para codornas europeias.

Portanto, além da evidente diferença entre os valores recomendados, é importante destacar a necessária atualização desses valores para que a mudança nas exigências nutricionais seja acompanhada ao longo do tempo.

Outro fator importante a ser considerado é o sexo das aves. Foi verificado que codornas fêmeas possuem desempenho superior ao dos machos, mas em compensação um rendimento de carcaça inferior (OLIVEIRA et al. 2002). O rendimento de carcaça inferior ao dos machos pode ser explicado pelo desenvolvimento do aparelho reprodutivo da fêmea e pela maior deposição de gordura na carcaça (MARKS 1993, OGUZ et al. 1996).

Com base no que foi exposto, o objetivo deste estudo foi determinar a exigência nutricional de PB para codornas de corte de ambos os sexos na fase de 1 a 21 dias e de 22 a 45 dias sobre o desempenho zootécnico e sobre as características de carcaça.

\section{MATERIAL E MÉTODOS}

Codornas europeias da linhagem comercial de corte da granja Fujikura ${ }^{\circledR}$ foram alojadas num delineamento inteiramente casualizado em esquema fatorial $5 \times 2$, sendo cinco níveis de PB e dois sexos avaliados. As avaliações foram realizadas em duas fases: fase inicial ( 1 a 21 dias) e de crescimento (22 a 45 dias). Na fase inicial foram utilizadas 1.800 codornas alimentadas com teores proteicos de 20,0, 22,5, $25,0,27,5$ e 30,0\%, para machos e fêmeas, com 30 aves por boxe. Na fase de crescimento foram utilizadas 1.620 codornas submetidas aos seguintes níveis de PB: 17,5, 19,5, 22,0, 24,5 e 27,0\%, para machos e fêmeas, com 27 aves por boxe. Os níveis de PB estudados foram estabelecidos a partir do recomendado por SILVA \& COSTA (2009), sendo dois níveis abaixo e dois níveis acima com equidistância de $2,5 \%$. As dietas foram fareladas e formuladas a base de milho e farelo de soja de acordo com as exigências nutricionais e a composição dos alimentos preconizadas por SILVA \& COSTA (2009) (Tabela 1). O valor de energia metabolizável utilizado como referência para óleo de soja foi baseado em ROSTAGNO et al. (2005). Água e ração foram fornecidas ad libitum.

Os ensaios experimentais foram conduzidos em galpão de alvenaria, com cobertura de telhas de barro e dividido em 60 boxes com $1 \mathrm{~m}^{2}$ cada, os quais foram providos de bebedouros do tipo copo de pressão, comedouros tubulares e cama de casca de arroz. A densidade das aves diminuiu de uma fase para outra, buscando o melhor conforto e densidade de criação. Para não haver influência do peso inicial das aves sobre o desempenho, o alojamento em cada fase foi feito de acordo com o peso corporal das codornas, buscando a homogeneidade entre os boxes. O peso médio inicial das codornas foi de $10,17 \pm$ $0,13 \mathrm{~g}$, e de $149,15 \pm 7,26 \mathrm{~g}$, para os ensaios da fase inicial (1 dia de idade) e da fase de crescimento (22 dias de idade), respectivamente. O aquecimento foi realizado com lâmpadas infravermelhas de $250 \mathrm{~W}$ dentro dos boxes e campânulas a gás distribuídas ao longo do corredor central do galpão. As temperaturas médias máximas e mínimas registradas no período experimental foram 26,5 e $13,9{ }^{\circ} \mathrm{C}$, respectivamente.

As variáveis de desempenho avaliadas foram: ganho de peso, consumo de ração, conversão alimentar e viabilidade. Os dados de desempenho foram coletados nos períodos de 1 a 21 dias e 22 a 45 dias de idade, considerando o boxe como unidade experimental, totalizando seis repetições por tratamento. 
Tabela 1. Composição centesimal das dietas experimentais.

Table 1. Centesimal composition of experimental diets.

\begin{tabular}{|c|c|c|c|c|c|c|c|c|c|c|}
\hline \multirow{3}{*}{ Ingredientes (\%) } & \multicolumn{10}{|c|}{ Níveis de proteína bruta (\%) por fase de criação } \\
\hline & \multicolumn{5}{|c|}{ Inicial (1 a 21 dias) } & \multicolumn{5}{|c|}{ Crescimento (22 a 45 dias) } \\
\hline & 20,0 & 22,5 & 25,0 & 27,5 & 30,0 & 17,0 & 19,5 & 22,0 & 24,5 & 27,0 \\
\hline Milho & 60,81 & 55,89 & 50,14 & 43,12 & 36,14 & 69,72 & 64,54 & 59,35 & 54,17 & 48,98 \\
\hline Farelo de soja & 29,56 & 36,14 & 42,18 & 48,26 & 54,53 & 17,3 & 21,89 & 26,47 & 31,06 & 35,65 \\
\hline Óleo de soja & 0,25 & 0,25 & 0,5 & 1,17 & 1,85 & 0,5 & 0,5 & 0,5 & 0,5 & 0,5 \\
\hline Glúten 60 & 0,25 & 0,5 & 1,23 & 2,11 & 2,84 & 3,53 & 5,22 & 6,92 & 8,62 & 10,32 \\
\hline L-Lisina & 0,05 & 0,02 & 0,02 & 0,01 & - & - & . & - & 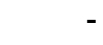 & \\
\hline DL-Metionina & 0,07 & 0,11 & 0,14 & 0,18 & 0,21 & 0,06 & 0,07 & 0,09 & 0,1 & 0,11 \\
\hline Calcário & 0,92 & 0,95 & 0,98 & 1 & 1,03 & 0,74 & 0,77 & 0,8 & 0,83 & 0,85 \\
\hline Sal Comum & 0,32 & 0,33 & 0,34 & 0,34 & 0,35 & 0,28 & 0,28 & 0,29 & 0,29 & 0,3 \\
\hline F carne/c & 3,44 & 3,18 & 2,95 & 2,72 & 2,48 & 2,97 & 2,77 & 2,57 & 2,37 & 2,16 \\
\hline Caulim & 3,73 & 2,03 & 0,93 & 0,5 & - & 4,49 & 3,55 & 2,61 & 1,67 & 0,73 \\
\hline Premix $^{1}$ & 0,60 & 0,60 & 0,60 & 0,60 & 0,60 & 0,40 & 0,40 & 0,40 & 0,40 & 0,40 \\
\hline Composic & \multicolumn{10}{|c|}{ Níveis nutricionais } \\
\hline Energia metabolizável, kcal/kg & 2.900 & 2.900 & 2.900 & 2.900 & 2.900 & 3.050 & 3.050 & 3.050 & 3.050 & 3.050 \\
\hline Proteína bruta, \% & 20,00 & 22,50 & 25,00 & 27,50 & 30,00 & 17,00 & 19,50 & 22,00 & 24,50 & 27,00 \\
\hline Fibra bruta, \% & 3,49 & 3,89 & 4,23 & 4,54 & 4,88 & 2,79 & 3,04 & 3,30 & 3,55 & 3,80 \\
\hline Cálcio, \% & 0,85 & 0,85 & 0,85 & 0,85 & 0,85 & 0,70 & 0,70 & 0,70 & 0,70 & 0,70 \\
\hline Fósforo disponível, \% & 0,32 & 0,32 & 0,32 & 0,32 & 0,32 & 0,27 & 0,27 & 0,27 & 0,27 & 0,27 \\
\hline Lisina dig., \% & 1,09 & 1,23 & 1,37 & 1,50 & 1,64 & 0,79 & 0,90 & 1,02 & 1,13 & 1,25 \\
\hline Metionin & 0,52 & 0,59 & 0,66 & 0,73 & 0,80 & 0,34 & 0,39 & 0,45 & 0,50 & 0,56 \\
\hline Metion & 0,83 & 0,93 & 1,04 & 1,14 & 1,25 & 0,62 & 0,71 & 0,80 & 0,89 & 0,98 \\
\hline Treonina dig., \% & 0,69 & 0,77 & 0,86 & 0,95 & 1,03 & 0,58 & 0,67 & 0,75 & 0,84 & 0,92 \\
\hline Valina dig., \% & 0,86 & 0,97 & 1,07 & 1,18 & 1,29 & 0,75 & 0,86 & 0,97 & 1,07 & 1,18 \\
\hline Sódio, \% & 0,17 & 0,17 & 0,17 & 0,17 & 0,17 & 0,15 & 0,15 & 0,15 & 0,15 & 0,15 \\
\hline Ácido linoleico, \% & 1,44 & 1,39 & 1,32 & 1,24 & 1,15 & 1,58 & 1,53 & 1,49 & 1,44 & 1,40 \\
\hline
\end{tabular}

${ }^{1}$ Níveis de garantia por kg de ração para a fase inicial: Vitamina A 9996 U.I; Vitamina D3 1248 U.I; Vitamina E 20,16 U.I; Vitamina K3 3 mg; Vitamina B1 3 mg; Vitamina B2 6 mg; Vitamina B6 4 mg; Vitamina B12 0,01008 mg; Niacina 40000 mg; Ácido Pantotênico 30 mg; Colina 260 g; Ácido Fólico 0,48 mg; Metionina 1580 mg; Cobre 7,99 mg; Ferro 499 mg; Manganês 0,07 mg; Zinco 49,99 mg; lodo 1,20 mg; Selênio 0,19 mg; Salinomicina $550 \mathrm{mg}$. Níveis de garantia por kg de ração para a fase final: Vitamina A 12000 U.I; Vitamina D3 3600 U.I; Vitamina E 180 U.l/kg; Vitamina K3 3,00 mg; Vitamina B1 3,60 mg; Vitamina B2 9,00 mg; Vitamina B6 6,00 mg; Vitamina B12 0,021 mg; Niacina 600 mg; Ácido Pantotênico 22,50 mg; Ácido Fólico 0,150 mg; Colina 510 mg; Ferro 7500 mg; Manganês 105 mg; Zinco 75 mg; Cobre $15 \mathrm{mg}$; lodo $1,80 \mathrm{mg}$; Selênio $0,30 \mathrm{mg}$.

A avaliação do rendimento de carcaça foi feita no $45^{\circ}$ dia de idade. Foram separadas quatro aves por boxe, sendo que cada ave foi considerada como uma unidade experimental, totalizando 24 repetições por tratamento. As codornas foram submetidas a jejum de oito horas, e na sequência foram pesadas, identificadas e submetidas ao abate de acordo com as seguintes etapas: insensibilização, sangria, escalda, depena, evisceração e resfriamento das carcaças. Foram pesadas as carcaças evisceradas quentes e após o resfriamento, desprovidas de cabeça e pés. Em seguida, as carcaças resfriadas foram encaminhadas para a sala de cortes, onde foram pesados os peitos com osso, pernas, asas e dorso. Por meio do peso vivo de cada ave foi avaliado o rendimento de carcaça eviscerada, e pelo peso de sua carcaça eviscerada foi calculado o rendimento de cortes (asas, pernas, peito e dorso) e de vísceras comestíveis (coração, fígado, moela).

Os resultados foram analisados com critério de $5 \%$ de significância por meio do software Statistical Analysis System (SAS 2012). Os dados foram submetidos à análise de variância por meio do procedimento GLM para verificar o efeito das doses de PB, do sexo das aves e da interação entre esses dois fatores. A estimativa do teor ideal de PB foi estabelecida por meio de análises de regressão, a qual foi calculada pelo desdobramento da soma de quadrados do teor de PB por meio de polinômios ortogonais.

\section{RESULTADOS E DISCUSSÃO}

Não houve interação entre os fatores sobre os dados de desempenho (Tabela 2). Na fase inicial (1 a 
21 dias), as codornas apresentaram maior o ganho de peso com valores de $25,5 \%$ de PB (Figura $1 \mathrm{~A}$ ). Os resultados das exigências para máximo ganho de peso nessa fase estão muito próximos aos valores encontrados na literatura nacional, quando consideradas as exigências propostas por SILVA \& COSTA (2009). Em contraste, trabalhos mais antigos na literatura demonstram melhores resultados de ganho de peso aos 21 dias de idade com dietas contendo maiores quantidades de proteína (30\% de PB) (CORRÊA et al. 2007). É possível que, com o avanço no uso de aminoácidos cristalinos, as exigências dos primeiros aminoácidos limitantes e essenciais estejam sendo bem atendidas, diminuindo a necessidade de formulações com altas teores de PB.

Tabela 2. Desempenho de codornas de corte de 1 a 21 dias de idade alimentadas com dietas contendo níveis crescentes de proteína bruta.

Table 2. Performance of 1 to 21 -day-old quails fed diets containing increasing levels of crude protein.

\begin{tabular}{|c|c|c|c|c|c|c|c|c|c|}
\hline \multirow{3}{*}{\multicolumn{2}{|c|}{ Efeitos ${ }^{1}$}} & \multicolumn{8}{|c|}{ Desempenho $^{2}$} \\
\hline & & \multicolumn{4}{|c|}{1 a 21 dias } & \multicolumn{4}{|c|}{22 a 45 dias } \\
\hline & & GP & $\mathrm{CR}$ & $\mathrm{CA}$ & VB & GP & $\mathrm{CR}$ & $\mathrm{CA}$ & VB \\
\hline & $-5,0 \%$ & 121,4 & 251,4 & 1,98 & 94,03 & 148,7 & 796,1 & 5,45 & 96,97 \\
\hline & $-2,5 \%$ & 132,2 & 257,2 & 1,88 & 95,00 & 145,0 & 798,7 & 5,59 & 96,30 \\
\hline & Referência & 133,5 & 254,6 & 1,83 & 93,61 & 148,9 & 773,8 & 5,15 & 97,84 \\
\hline & $+2,5 \%$ & 129,3 & 253,3 & 1,83 & 88,61 & 145,7 & 785,4 & 5,53 & 97,64 \\
\hline & $+5,0 \%$ & 127,3 & 252,3 & 1,82 & 85,41 & 148,4 & 813,6 & 5,58 & 97,98 \\
\hline \multirow{2}{*}{ Sexo } & Machos & 129,2 & 255,2 & 1,88 & 92,44 & 126,4 & 745,7 & 5,90 & 95,77 \\
\hline & Fêmeas & 128,3 & 252,3 & 1,85 & 90,22 & 167,6 & 838,2 & 5,07 & 98,85 \\
\hline \multicolumn{2}{|c|}{ CV (\%) } & 6,57 & 4,17 & 3,16 & 6,43 & 15,59 & 11,04 & 14,06 & 4,3 \\
\hline \multicolumn{2}{|c|}{ Fontes de variação } & \multicolumn{8}{|c|}{ Probabilidades } \\
\hline \multicolumn{2}{|l|}{ PB } & 0,009 & 0,698 & $<0,001$ & 0,001 & 0,710 & 0,855 & 0,530 & 0,839 \\
\hline \multicolumn{2}{|l|}{ Sexo } & 0,669 & 0,292 & 0,078 & 0,149 & $<0,001$ & $<0,001$ & $<0,001$ & 0,007 \\
\hline \multicolumn{2}{|c|}{ PB $\times$ Sexo } & 0,166 & 0,832 & 0,613 & 0,122 & 0,797 & 0,818 & 0,533 & 0,660 \\
\hline
\end{tabular}

${ }^{1}$ Os teores de referência de proteína bruta (PB) para a fase inicial (1 a 21 dias) e de crescimento (22 a 45 dias) foram de 25,0 e $22,0 \%$, respectivamente, (SILVA \& COSTA, 2009). Os demais tratamentos foram obtidos reduzindo ou aumentando os teores de PB em doses equidistantes de $2,5 \%$.

${ }^{2} \mathrm{GP}$, ganho de peso médio (g); CR, consumo de ração médio (g), CA, conversão alimentar, VB, viabilidade (\%). Dados provenientes de seis repetições por tratamento, com $n=30$ ( 1 a 21 dias) e $n=27$ (22 a 45 dias) dentro da repetição.

A melhor conversão alimentar foi encontrada com 27,06\% de inclusão de PB na dieta (Figura 1B). FRIDRICH et al. (2005) encontraram melhor conversão alimentar utilizando $25,5 \%$ de PB no período de 18 a 28 dias, próximo ao proposto no presente estudo, visto que a medida que a idade das aves evolui a exigência por PB vai diminuindo, devido à redução na taxa de crescimento muscular das aves (MARCARI et al. 2002). Os resultados do presente estudo estão próximos também de DUMONT et al. (2017), que encontraram melhor desempenho utilizando $26 \%$ de PB. A viabilidade diminuiu linearmente com o aumento da PB, demonstrando que o aumento dos valores proteicos da dieta pode elevar a mortalidade das aves (Figura 1C). É possível que as doses mais elevadas de PB na dieta tenham sobrecarregado o metabolismo para eliminar as quantidades excessivas de nitrogênio, prejudicando as demais funções do organismo.

A divergência entre as doses de PB recomendadas para ganho de peso e para a conversão alimentar, de $25,5 \%$ e $27,06 \%$, respectivamente, ocorreu porque os valores de consumo de ração foram numericamente menores em doses acima de $25,0 \%$ de PB. Portanto, a queda no ganho de peso foi acompanhada pelo decréscimo dos valores de consumo de ração (não em mesma proporção), piorando a razão entre ambos somente após $27,06 \%$, apesar do ganho de peso estar sendo prejudicado logo após os $25,5 \%$ de PB. Com isso, nossa recomendação para a fase inicial é de $25,5 \%$ de PB, desde que os aminoácidos limitantes sejam atendidos na formulação da dieta. Além disso, doses elevadas de PB diminuíram a sobrevivência das codornas, devendo ser evitadas, pois baixos índices de mortalidade são muito importantes no cálculo de desempenho de um lote.

No período de 22 a 45 dias (Tabela 2), não houve efeito dos níveis de PB sobre o desempenho das codornas. Esses resultados demonstram a capacidade de produzir codornas de corte com dietas contendo 
doses proteicas abaixo do que é preconizado. Em trabalho recente, RIBEIRO et al. (2016) observaram a possibilidade do uso de dietas com níveis de PB abaixo dos $22 \%$. WEN et al. (2017) ressaltaram que a maioria dos experimentos utilizam poucos aminoácidos cristalinos ao formular as dietas, e talvez o acréscimo de outros aminoácidos como a treonina, a valina, o triptofano e a arginina, possa proporcionar dietas eficazes e com menor PB.
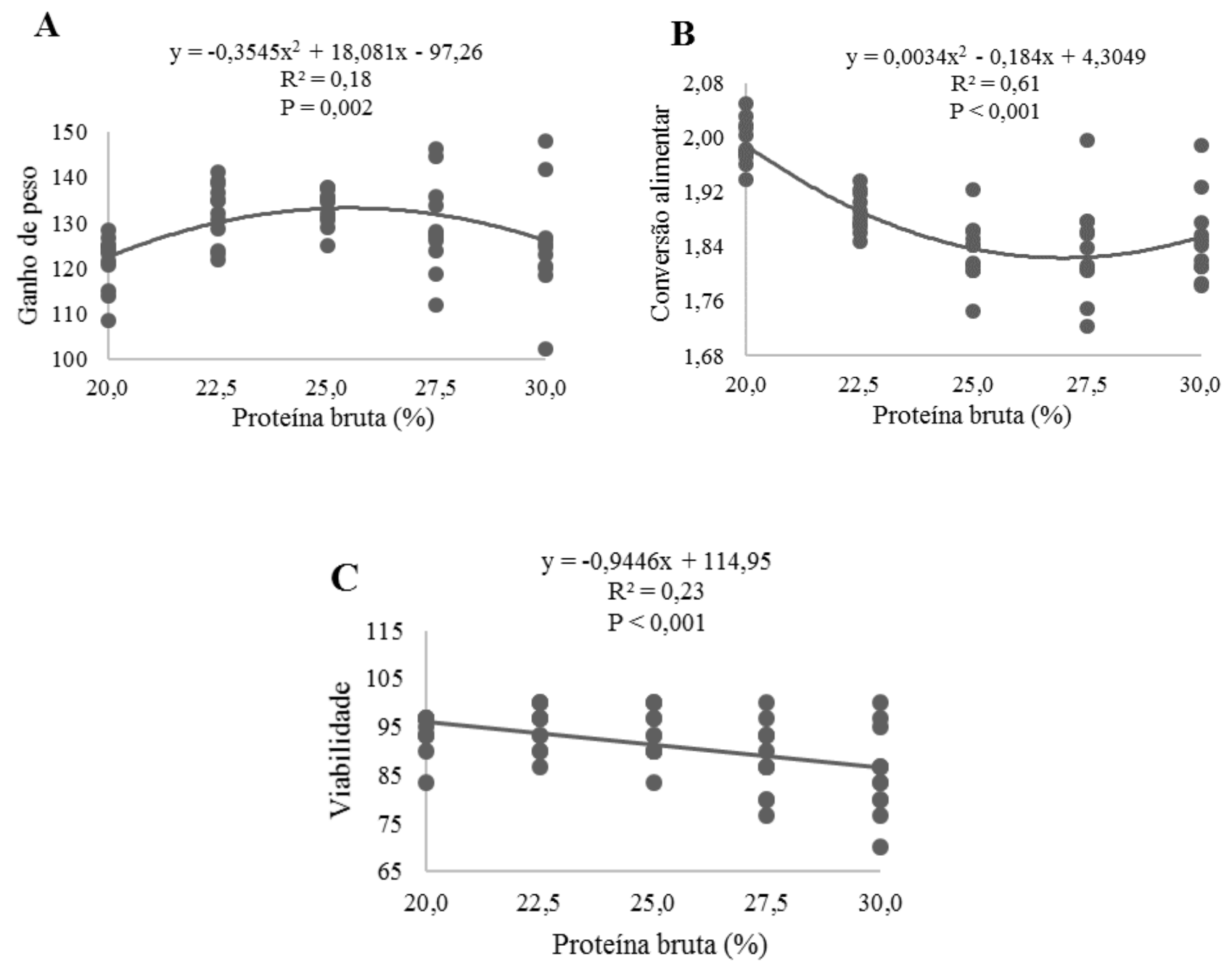

Figura 1. (A) Ganho de peso de codornas de corte aos 21 dias de idade, alimentadas com níveis crescentes de proteína bruta. (B) Conversão alimentar de codornas de corte aos 21 dias de idade, alimentadas com níveis crescentes de proteína bruta. (C) Viabilidade de codornas de corte aos 21 dias de idade alimentadas com níveis crescentes de proteína bruta.

Figure 1. (A) Quails weight gain at 21 days of age fed with increasing levels of crude protein (B) Feed conversion of quails at 21 days of age fed with increasing levels of crude protein. (C) Viability quails at 21 days of age fed with increasing levels of crude protein.

Outro ponto é o conceito de proteína ideal para a alimentação de codornas europeias, no qual é fornecida uma dieta mais adequada quanto aos níveis de aminoácidos requeridos para máximo desempenho (SUIDA 2001). No entanto, é preciso ter cautela e responder até quanto a PB pode ser diminuída sem comprometer o desempenho.

Com relação ao efeito do sexo das aves, observou-se que as fêmeas tiveram desempenho superior ao dos machos, demonstrando melhores aptidões para ganho de peso, conversão alimentar e viabilidade, estando de acordo com a literatura (MARKS 1993, OGUZ et al. 1996). O maior ganho de peso das fêmeas deve ser prudentemente interpretado, pois com a aproximação da maturidade sexual as fêmeas passam a depositar maior quantidade de gordura abdominal, o que implica em um menor rendimento de carcaça (CARON et al. 1990, OGUZ et al. 1996, RAJINI \& NARAHARI 1998). Por isso, trabalhos que avaliam a composição corporal e decompõem o ganho de peso em frações de gordura, nitrogênio e água são sugeridos para o futuro. 
As variáveis de características de carcaça são apresentadas na Tabela 3. Não houve efeito dos fatores sobre o rendimento de asa e coxa + sobrecoxa, corroborando com CORRÊA et al. (2008). Os machos obtiveram resultados superiores no rendimento de carcaça: rendimento de carcaça fria, quente e dorso. O maior rendimento de carcaça dos machos ocorre devido ao maior peso do trato reprodutivo e acúmulo de gordura abdominal nas fêmeas (CARON et al. 1990, OGUZ et al. 1996, RAJINI \& NARAHARI 1998, TABOADA 1998). Já as fêmeas, obtiveram maiores rendimentos de cortes: peito e moela. Em paralelo, CORRÊA et al. (2008) também encontraram maior rendimentos de peito nas fêmeas. Os resultados de rendimento de peito demonstraram ausência de efeito da dose proteica, discordando de OTUTUMI et al. (2009), que encontraram melhor rendimento de peito com nível de $26,47 \%$ de PB. Já CORRÊA (2006), assim como o presente estudo, não encontrou efeitos significativos de PB para o rendimento de peito.

Tabela 3. Características de carcaça de codornas de corte abatidas aos 45 dias de idade.

Table 3. Carcass traits of quails slaughtered at 45 days of age.

\begin{tabular}{|c|c|c|c|c|c|c|c|c|c|c|}
\hline \multirow[t]{2}{*}{ Efeitos* $^{*}$} & & \multicolumn{9}{|c|}{ Características de carcaça $(\%)^{* *}$} \\
\hline & & $C Q$ & CF & Peito & Dorso & Asa & $\mathrm{C}+\mathrm{S}$ & Coração & Moela & Fígado \\
\hline \multirow{5}{*}{$\mathrm{PB}(\%)$} & $-5,0 \%$ & 63,46 & 69,61 & 34,05 & 18,27 & 9,67 & 26,53 & 1,28 & 3,27 & 3,46 \\
\hline & $-2,5 \%$ & 63,81 & 69,00 & 33,92 & 18,07 & 9,66 & 26,47 & 1,28 & 3,47 & 3,16 \\
\hline & Referência & 62,09 & 68,81 & 34,20 & 18,25 & 9,66 & 26,51 & 1,23 & 3,37 & 3,01 \\
\hline & $+2,5 \%$ & 64,94 & 70,24 & 33,40 & 19,22 & 9,66 & 26,91 & 1,25 & 3,15 & 2,88 \\
\hline & $+5,0 \%$ & 63,63 & 68,29 & 34,07 & 18,68 & 9,55 & 26,50 & 1,30 & 3,38 & 3,05 \\
\hline \multirow{2}{*}{ Sexo } & Macho & 66,33 & 72,83 & 33,07 & 19,06 & 9,62 & 26,51 & 1,29 & 3,10 & 2,31 \\
\hline & Fêmea & 60,85 & 65,55 & 34,77 & 17,91 & 9,66 & 26,65 & 1,25 & 3,57 & 3,92 \\
\hline \multicolumn{2}{|l|}{$\mathrm{CV}(\%)$} & 8,75 & 7,33 & 6,59 & 9,79 & 6,28 & 5,15 & 12,95 & 20,61 & 36,88 \\
\hline \multicolumn{2}{|c|}{ Fontes de variação } & \multicolumn{9}{|c|}{ Probabilidades } \\
\hline \multicolumn{2}{|l|}{$\overline{\mathrm{PB}}$} & 0,214 & 0,444 & 0,559 & 0,385 & 0,916 & 0,572 & 0,328 & 0,246 & 0,015 \\
\hline \multicolumn{2}{|c|}{$\begin{array}{l}\text { Sexo } \\
P R \times \text { Sexo }\end{array}$} & $<0,001$ & $<0,001$ & $<0,001$ & $<0,001$ & 0,614 & 0,427 & 0,056 & $<0,001$ & $<0,001$ \\
\hline \multicolumn{2}{|c|}{ PB $\times$ Sexo } & 0,704 & 0,079 & 0,705 & 0,108 & 0,854 & 0,308 & 0,001 & 0,300 & $<0,001$ \\
\hline
\end{tabular}

${ }^{*} \mathrm{O}$ teor de referência de proteína bruta (PB) para a fase de crescimento (22 a 45 dias) foi de 22,0\% (SILVA \& COSTA 2009). Os demais tratamentos foram obtidos reduzindo ou aumentando os teores de PB em doses equidistantes de $2,5 \%$.

${ }^{* *} \mathrm{CQ}$, Carcaça quente, $\mathrm{CF}$, carcaça fria, $\mathrm{C}+\mathrm{S}$, coxa+sobrecoxa. Os rendimentos de carcaça quente e fria foram calculados com relação ao peso vivo. O rendimento de vísceras comestíveis foi obtido com relação ao peso da carcaça quente eviscerada. O rendimento de cortes foi obtido com relação ao peso da carcaça fria eviscerada. Dados provenientes de 24 repetições por tratamento, com $n=1$ dentro da repetição.

Houve interação dos fatores sexo e PB no rendimento de coração e fígado. O rendimento de coração nos machos reduziu linearmente com o aumento de PB, enquanto que nas fêmeas o efeito foi quadrático, com menor rendimento com $21,10 \%$ de PB (Figura 2A). O rendimento de fígado se comportou de forma quadrática em ambos os sexos em função das doses de PB, com menor rendimento com 21,43 e $25,47 \%$ de PB para macho e fêmea, respectivamente (Figura 2B).

Foi observado no presente estudo maior rendimento de fígado nas fêmeas. Devido ao fígado ser responsável pela síntese lipídica nas aves, quando as codornas atingem a maturidade sexual, há um aumento na sua atividade metabólica, fazendo com que o conteúdo hepático das fêmeas seja maior que nos machos. Esses mesmos achados foram observados anteriormente na literatura (TABOADA 1998, CORRÊA et al. 2008, FERREIRA et al. 2014). 

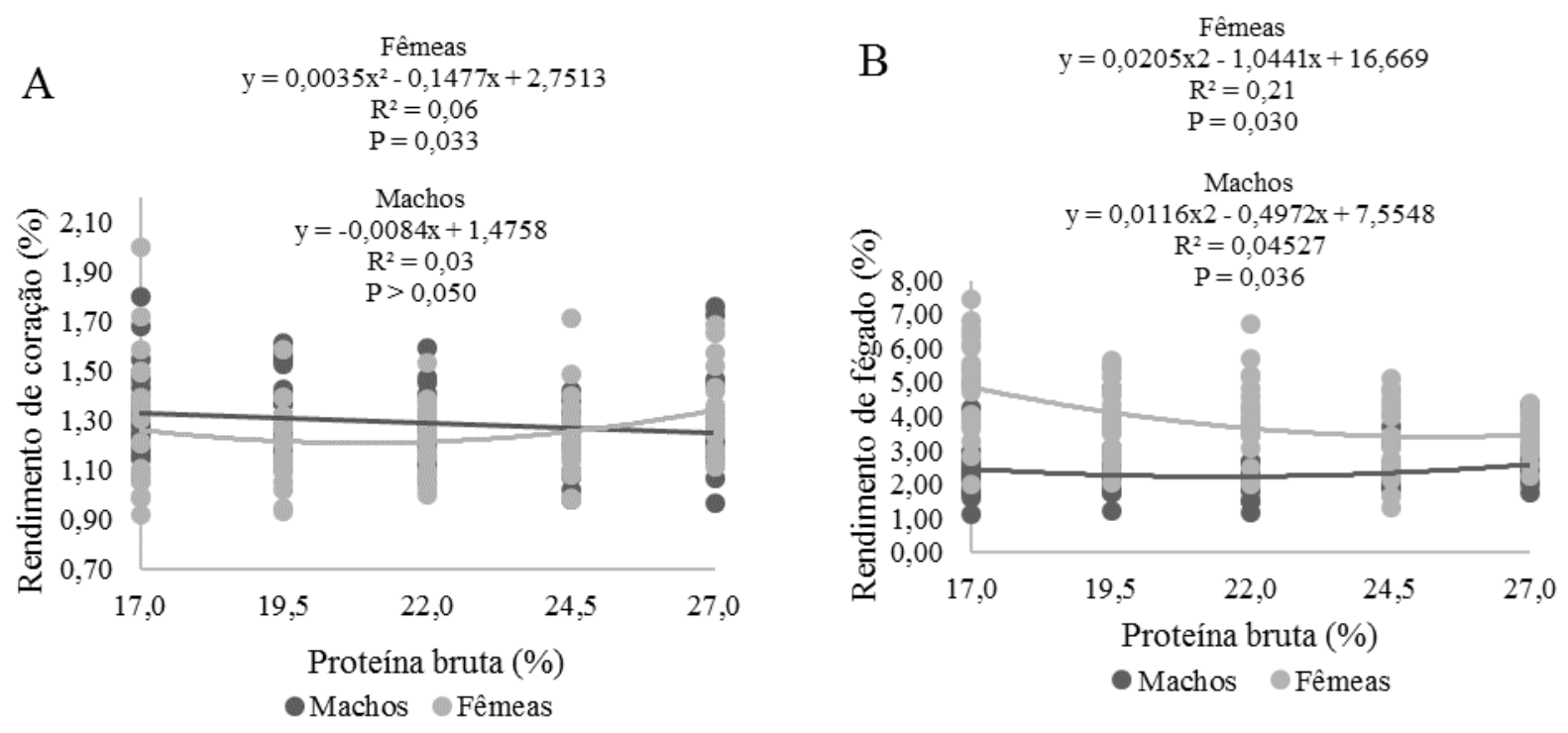

Figura 2. (A) Rendimento de coração de codornas de corte aos 45 dias de idade, alimentadas com níveis crescentes de proteína bruta. (B) Rendimento de fígado de codornas de corte aos 45 dias de idade, alimentadas com níveis crescentes de proteína bruta.

Figure 2. (A) Quails heart yield at 45 days of age, fed with increasing levels of crude protein. (B) Quails liver yeld at 45 days of age, fed with increasing levels of crude protein.

\section{CONCLUSÃO}

Os resultados de desempenho demonstraram que a dose ideal de PB de 1 a 21 dias é de $25,5 \%$ de PB. Na fase de 22 a 45 dias, os teores de PB avaliados não influenciam o desempenho, indicando que a quantidade ideal de PB nessa fase pode estar abaixo do que vem sendo preconizado.

O sexo das codornas tem influência no desempenho de 22 a 45 dias, fase em que as fêmeas possuem desempenho superior ao dos machos. No entanto, o maior crescimento das fêmeas deve ser ponderado, pois as mesmas possuem menor rendimento de carcaça. Se o interesse de produção for para cortes nobres, as fêmeas podem ser a melhor escolha devido ao maior rendimento de peito, moela e fígado.

\section{REFERÊNCIAS}

ALETOR VA et al. 2000. Low protein amino acid-supplemented diets in broiler chickens: Effects on performance, carcass characteristics, whole- body composition and efficiencies of nutrient utilization. Journal of the Science of Food and Agriculture 80: 547-554.

BREGENDAHL $\mathrm{K}$ et al. 2002. Effect of low-protein diets on growth performance and body composition of broiler chicks. Poultry Science 81: 1156-1167.

CARON N et al. 1990. Mass selection for 45-day body weight in Japanese quail: selection response, carcass composition, cooking properties, and sensory characteristics. Poultry Science 69: 1037-1045.

CORREAA AB et al. 2007. Exigências em proteína bruta para codornas de corte EV1 em crescimento. Arquivo Brasileiro Medicina Veterinária Zootecnia 59: 1278-1286.

CORREAA GSS. 2006. Exigências nutricionais de diferentes grupos genéticos de codornas de corte. Tese (Doutorado em Produção Animal). Belo Horizonte: UFMG. 175p.

CORRÊA GSS et al. 2008. Exigência de proteína bruta e energia metabolizável em codornas de corte durante a fase de crescimento. Arquivo Brasileiro de Medicina Veterinária e Zootecnia 59: 488-495.

DUMONT MA et al. 2017. Crude protein in diets of european quails. Ciência Animal Brasileira 18: 1-12.

FERREIRA F et al. 2014. Características de carcaça de codornas de corte EV1 alimentadas com diferentes níveis de metionina+cistina total. Arquivo Brasileiro de Medicina Veterinária e Zootecnia 66: 1855-1864.

FRIDRICH AB et al. 2005. Exigência de proteína bruta para codornas europeias no período de crescimento. Arquivo Brasileiro de Medicina Veterinária e Zootecnia 57: 261-265.

MARCARI M et al. 2002. Fisiologia aviária aplicada a frangos de corte. 2.ed. Jaboticabal: FUNEP. 230p.

MARKS HL. 1993. The influence of dietary protein level on body weight of japanese quail lines selected under high- and low-protein diets. Poultry Science 72: 1012-1017.

NRC. 1994. National Research Council. Nutrient requirements of domestic animals. 9.ed. Washington: National Academy Press. 176p.

OGUZ I et al. 1996. Body weights, carcass characteristics, organ weights, abdominal fat and lipid content of liver and carcass on two lines of japanese quail (Coturnix coturnix japonica), unselected and selected for four week body weight. 
British Poultry Science 37: 579-588.

OLIVEIRA EG et al. 2002. Desempenho produtivo de codornas de ambos os sexos para corte alimentadas com dietas com quatro níveis protéicos. Archives of Veterinary Science 7: 75-80.

OTUTUMI LK et al. 2009. Efeito do probiótico sobre o desempenho, rendimento de carcaça e exigências nutricionais de proteína bruta de codornas de corte. Revista Brasileira de Zootecnia 38: 299-306.

RAJINI RA \& NARAHARI D. 1998. Dietary energy and protein requirements of growing Japanese quails in the tropics. Indian Journal of Animal Sciences 68: 1082-1086.

REZENDE MJM et al. 2004. Desempenho produtivo e biometria das vísceras de codornas francesas alimentadas com diferentes níveis de energia metabolizável e proteína bruta. Acta Scientiarum Animal Sciences 26: 353-358.

RIBEIRO TLA et al. 2016. Diferentes níveis de proteína e energia sobre o comportamento fisiológico e desempenho de codornas europeias no semiárido brasileiro. Journal of Animal Behaviour and Biometeorology 4: 76-83.

ROSTAGNO HS et al. 2005. Tabelas brasileiras para aves e suínos: composição de alimentos e exigências nutricionais. 2.ed. Viçosa: UFV. 488p.

SILVA JHV \& COSTA FGP 2009. Tabela para codornas japonesas e europeias. 2.ed. Jaboticabal: FUNEP. 110p.

SAS. 2012. Statistical Analysis System. SAS Online Doc. Version 9.1.3. Cary: SAS Institute.

SUIDA D. 2001. Formulação por proteína ideal e consequências técnicas, econômicas e ambientais. In: Simpósio Internacional de Nutrição Animal: Proteína Ideal, Energia Líquida e Modelagem, 1. Santa Maria. Anais... p.27-43.

TABOADA P. 1998. Efectos del sexo sobre los rendimientos en la codorniz japonesa (Coturnix coturnix japonica) y la composición química de su carne. Revista Cubana de Ciencia Avícola 22: 19-24.

VELOSO RC et al. 2012. Níveis de proteína bruta e energia metabolizável em uma linhagem de codorna de corte. Acta Scientiarum Animal Sciences 34: 169-174.

WEN ZG et al. 2017. Effects of low-protein diets on growth performance and carcass yields of growing French meat quails (France coturnix coturnix). Poultry Science 96: 1364-1369. 